BULLETIN Bulletin hispanique

HISPANIQUE Université Michel de Montaigne Bordeaux

116-2 | 2014

Référentialité/autoréférentialité dans le roman espagnol contemporain : bilan et perspectives

\title{
La Barcelona de Manuel Vázquez Montalbán (1939-2003) y la Marsella de Jean-Claude Izzo (1945-2000)
}

referencia y reverencia

Georges Tyras

\section{OpenEdition}

Journals

Edición electrónica

URL: http://journals.openedition.org/bulletinhispanique/3489

DOI: 10.4000/bulletinhispanique.3489

ISBN: $979-10-300-0156-3$

ISSN: 1775-3821

Editor

Presses universitaires de Bordeaux

Edición impresa

Fecha de publicación: 1 diciembre 2014

Paginación: 671-683

ISBN: 978-2-86781-963-6

ISSN: 0007-4640

Referencia electrónica

Georges Tyras, «La Barcelona de Manuel Vázquez Montalbán (1939-2003) y la Marsella de Jean-

Claude Izzo (1945-2000)», Bulletin hispanique [En línea], 116-2 | 2014, Publicado el 01 diciembre 2017, consultado el 21 abril 2019. URL : http://journals.openedition.org/bulletinhispanique/3489; DOI : 10.4000/bulletinhispanique.3489 


\title{
La Barcelona de Manuel Vázquez Montalbán (1939-2003) y la Marsella de Jean-Claude Izzo (1945-2000): referencia y reverencia
}

\author{
GEORGES Tyras \\ Université Stendhal, Grenoble 3
}

Pour le marseillais Izzo comme pour le barcelonais Vázquez Montalbán, la ville est moins un cadre romanesque qu'un personnage à part entière, en lequel sincarnent les antagonismes sociaux, les oppressions économiques et les sujétions politiques. Le lyrisme de l'écriture des deux auteurs est ainsi mis au service d'un traitement engagé de l'espace qui fait de celui-ci la constante métaphore de la tragédie de l'homme contemporain.

Mots-clés : roman noir, ville, espace, écriture, engagement.

Para el marsellés Izzo como para el barcelonés Vázquez Montalbán, la ciudad es menos un marco novelesco que un personaje de pleno derecho, en el que se encarnan los antagonismos sociales, las opresiones económicas y las sujeciones politicas. El lirismo de la escritura de ambos autores se pone entonces al servicio de un tratamiento comprometido del espacio que lo convierte en la constante metáfora del hombre contemporáneo.

Palabras Claves: novela negra, ciudad, espacio, escritura, compromiso.

Both Marseille-born Izzo and Barcelona-born Vázquez Montalbán consider cities less a settings for their novels than as full-fledged characters, embodying social antagonisms, economic oppressions and political subjections. The two novelists' lyric writing is dedicated to a committed treatment of space, which is thus turned into a recurrent metaphor for the tragedy of contemporary man.

Keywords: "roman noir", city, space, writing, commitment. 
Sous le soleil, il n'y a pas de mystères, seulement des tragédies. Jean Giono

J

ean-Claude Izzo tuvo la oportunidad de conocer a Manuel Vázquez Montalbán con motivo de una estancia en Barcelona, por los años 83 u 84, y de la escritura en colaboración con Andreu Martín del guión de una película un tanto experimental, que se rodó, dirigida por Manuel Esteban, pero no se llegó a difundir ${ }^{1}$. La película se llama Olimpicamente muerto y Manuel Vázquez Montalbán desempeña en ella su propio papel, explicando cómo escribe las novelas de Carvalho.

Otra anécdota, más personal, también da constancia de que ambos escritores se conocían y se apreciaban: cuando salió en noviembre del 97 la edición francesa de mi primer libro de conversaciones con el escritor barcelonés, Le désir de mémoire ${ }^{2}$, Jean-Claude Izzo entró en contacto conmigo para invitarnos, a Manuel Vázquez Montalbán y a mí, en la edición del año siguiente del festival de literatura de Saint-Malo, Étonnants voyageurs. El viajero de Barcelona no pudo liberarse. Yo fui y estuve bastante con Jean-Claude Izzo; entre nosotros nació la intención de realizar un libro de conversaciones similar al ya publicado sobre Montalbán, porque entre ambos había evidentes paralelismos de aprehensión del mundo real y del mundo de la escritura. El proyecto no se llevó a cabo, por la desaparición precoz de Jean-Claude Izzo. En aquella fecha (enero del 2000), acababa de salir Soleá, el tercer episodio de su trilogía; por su parte, Manuel Vázquez Montalbán publicaba El hombre de mi vida, al tiempo que trabajaba en la redacción de Milenio Carvalho, que tuvo que conocer una edición póstuma ${ }^{3}$. Para la crítica, eran obvias las afinidades entre los dos escritores, específicamente en su relación con el marco urbano:

Cela ne fait plus aucun doute. Jean-Claude Izzo sera à Marseille ce que Manuel Vázquez Montalbán est à Barcelone : le témoin privilégié d'une ville aux nuances fanfaronnes et passionnées, lumineuse et trouble, rebelle à toute approche touristiqué.

Una manifestación de este apego compartido es que ambos escritores han publicado sendos ensayos de acercamiento a su ciudad. Jean-Claude Izzo con el sencillo título de Marseille, Manuel Vázquez Montalbán con el más complejo de Barcelonas, en plural 5 . Estos libros ofrecen de entrada imprescindibles claves

1. "Pendant dix ans [...], Jean-Claude Izzo avait posé sa plume et bourlingué aux quatre coins de la planète. Sur le chemin du retour, il sest longuement attardé chez Manuel Vázquez Montalbán, à Barcelone, pour coécrire un scénario. "C'est lui qui m’a enseigné qu'on pouvait marier l'huile d'olive et Chandler." Le mélange fonctionne. " escribe Pascal Dupont, «Izzo ou l'utopie en rade», L'Express, 20 mars 1997.

2. Manuel Vázquez Montalbán, Le désir de mémoire. Entretien avec Georges Tyras. Vénissieux, Éditions Paroles d'Aube, 1997.

3. Los dos textos se publicaron en Planeta, respectivamente en 2000 y 2003.

4. Philippe Nassif, "La melting culture de Marseille la rebelle ", L'Événement du Jeudi, 3 avril 1997.

5. Marseille. Textes de Jean-Claude Izzo. Photographies de Daniel Mordzinski. Paris, Hoëbeke, 2000 ; Manuel Vázquez Montalbán, Barcelonas. Barcelona, Empúries, 1987. 
para entender la relación mantenida por cada autor con su ciudad. La de JeanClaude Izzo, primero:

Marseille est, a toujours été, le port des exils [...]. Ici, celui qui débarque un jour sur le port, il est forcément chez lui. D'où que l'on vienne, on est chez soi à Marseille. [...] C'est pour ça que j'aime cette ville, ma ville. Elle est belle pour cette familiarité qui est comme du pain à partager entre tous. Elle n'est belle que par humanité. [...] Je suis marseillais. C'està-dire d'ici, passionnément, et de tous les ailleurs en même temps. Marseille, c'est ma culture du monde. Ma première éducation du monde. [...] Je crois à cela, à ce que j’ai appris dans les rues de Marseille, et qui me colle à la peau : l'accueil, la tolérance, le respect de l'autre, l'amitié sans concession et la fidélité, cette qualité essentielle de l'amour. J'aime croire - car j'ai été élevé ainsi - que Marseille, ma ville, n'est pas une fin en soi. Mais seulement une porte ouverte. Sur le monde, sur les autres. Une porte qui resterait ouverte, toujours ${ }^{6}$.

Y la relación de Manuel Vázquez Montalbán con Barcelona:

[...] casi toda mi literatura está hecha desde la barcelonía del espacio que comparto y del tiempo que he vivido. [...] En este caso se trata de la crónica de mi ciudad, implicando en ella todas las ciudades posibles, porque es tesis previa e imprescindible de este libro que, como toda obra de creación, Barcelona no es Barcelona, sino Barcelonas. [...] Todo escritor escribe para orientarse a sí mismo y mucho más si la materia de su escritura es una ciudad. Ojalá mis puntos cardinales sean asumidos por mis lectores presentes y futuros, Y si no fuera así, que piensen en la honestidad literaria de mi empeño, desde la evidencia de que lo honesto en literatura no tiene nada que ver con lo honesto en la vida cotidiana. Toda propuesta literaria está basada en deshonestidades intermediarias, la memoria, la cultura, el deseo, las palabras ${ }^{7}$.

Palabras incandescentes las de Jean-Claude Izzo, a manera de declaración de amor, desde una generosidad vital capaz de levantar montañas urbanas, palabras más meditabundas las de Manuel Vázquez Montalbán, desde un enfoque intelectual que le permite subrayar la dimensión reflexiva, o metaliteraria, de cualquier forma de escritura. Les une sin embargo su profundo interés por su ciudad, y sobre todo el proyecto de convertirla en protagonista de las historias que cuentan, historias o novelas negras, evidentemente.

Decir que el espacio urbano constituye el marco privilegiado de la novela negra es decir lo obvio. Desde los orígenes, el género explora el subsuelo de una sociedad de tipo urbano ${ }^{8}$-aunque existan notables excepciones- por la sencilla razón de que, como lo formula acertadamente el crítico Joan Ramón Resina, «[...] se observa una correspondencia entre la modernidad del género y el papel de la ciudad como motor de la modernización desde el siglo XVIII». Más esencialmente, precisa a continuación el ensayista, el decorado urbano se ofrece como un conjunto semiótico cuyo desciframiento forma parte de la labor del investigador: «Ni la soledad arquetípica del detective ni la visión fragmentada de la ciudad moderna pueden concebirse aisladas ${ }^{9}$.»

6. Marseille, op. cit. p. 15-16.

7. Barcelonas, op. cit., p. 7.

8. La expresión es de Manuel Vázquez Montalbán : «Así como la novela de espionaje explora el subsuelo de la historia, la novela negra explora el subsuelo de la sociedad.»

9. Joan Ramón Resina, Un cadáver en la cocina. La novela criminal en la cultura del desencanto. 
De hecho, tanto Izzo con Marsella como Vázquez Montalbán con Barcelona se niegan a contemplar su ciudad como un decorado, a reducirla a cualquier tipo de folclore estereotipado. La ciudad aparece tal como es, con su suciedad, su violencia, su pasión; su representación, lejos de ser eufemística, convoca las tintas negras y la brutalidad de la trama policiaca. Al mismo tiempo, la presencia permanente de la muerte, de un drama muchas veces de dimensión trágica (Chourmo; Los pájaros de Bangkok), del mar como espacio de una imposible huida al sur favorece que la ciudad sea el escenario del trágico destino del hombre. El marco urbano viene a ser una metáfora de la condición humana ${ }^{10}$.

Ambos escritores se someten a las obligaciones constitutivas de la escritura policiaca: el contexto urbano, un esquema narrativo codificado, un registro de idioma más bien coloquial, marcado por una fuerte oralidad (quizá más fuerte en el caso de Izzo que en el de Manuel Vázquez Montalbán), un ser fronterizo desde el punto de vista social como protagonista. Pepe Carvalho y Fabio Montale son primos hermanos, figuras prototípicas de las pautas genéricas heredadas de la poética norteamericana. Policía de izquierdas el uno y detective privado aséptico el otro, tan desencantado el uno como el otro, oriundos de la inmigración italiana para Montale y de la gallego-murciana para Carvalho, los dos protagonistas juegan con las normas y las ponen a distancia: ambos son gastrónomos exigentes, beben bastante y les gustan las mujeres; en el caso de Montale, el whisky es una marca selecta, Lagavulin, las mujeres amadas por los dos hombres son más que marginales (;Charo!), el sitio donde vive Montale es una casucha de pescador al borde del Mediterráneo cuando Pepe prefiere la sierra de Vallvidrera. En cuanto al relato, se autoriza numerosas y extensas digresiones reflexivas que abarcan la infancia, la amistad, la sociedad, las relaciones de poder y, sobre todo, la ciudad, Marsella o Barcelona. Es decir que en ambos casos, los escritores se apoyan con toda conciencia en los códigos y los estereotipos genéricos (una víctima, un asesino, un investigador, un proceso narrativo de investigación) para mejor trabajar con la simbólica del espacio, concebido a la manera cómo los sociólogos definen el lugar: un espacio identitario (en el sentido de que produce identidad), relacional (en el sentido de que significa una pertenencia), histórico (en el sentido de que da forma a las relaciones entre los hombres).

Este paralelismo incita a ahondar un poco en el examen de las afinidades entre ambos escritores, poniéndolas de realce en dos aspectos: el biográfico, con la dimensión lírica de la escritura, y el temático, con el tratamiento del espacio.

\section{DiMENSIÓN LÍRICA DE LA ESCRITURA}

Jean-Claude Izzo nace en Marsella en 1945, de padre italiano y de madre nacida en Marsella pero de origen español; un charnego en una ciudad francesa, por así decirlo. Se cría en las calles de la ciudad cuando ésta era el

Barcelona, Anthropos, 1997 (Contemporáneos, 48), citas p. 144 et 155.

10. Véase Françoise Demougin, "Izzo. Un étonnant voyageur", Recherches et travaux, ${ }^{\circ} 59$, 2001, Contraintes et dérives d'écriture, p. 141-149. 
cruce de posguerra de todos los exilios. Sus recuerdos de infancia, la vida familiar, el barrio, su formación de tornero-fresador, los primeros amoríos, están diseminados en su obra: Total Khéops, Chourmo, Soleá, que constituyen la trilogía de Fabio Montale ${ }^{11}$; Los marineros perdidos ${ }^{12}$; algún que otro cuento, como "Une rentrée en bleu de chine», que cuenta los placeres de la escuela secundaria ${ }^{13}$. Fabio Montale tiene recuerdos que se parecen a los de su autor; sobre su padre por ejemplo:

Il sortait vers cinq heures de l'après-midi [...]. J'avais grandi avec ses absences. Je n'ai jamais su si mon père avait eu des maîtresses. Il avait aimé ma mère, j’étais sûr de ça, mais la vie des deux restait pour moi un mystère (Total Khéops, 153-54).

Gennaro Izzo trabajaba en un bar e Isabel Navarro como modista. Dueño de un bar en una famosa plaza cerca del puerto viejo, la plaza de Lenche, lo es Fonfón, uno de los personajes secundarios más importantes de la trilogía. No diré nada del run-run de la máquina de coser de su madre evocado por Manuel Vázquez Montalbán en algún poema suyo ${ }^{14}$. Pero sí del apodo de la madre de Jean-Claude Izzo, Babette, que sirve para nombrar un personaje femenino clave en Soleá.

La familia Izzo, como muchas otras, fue expulsada de su barrio, Le Panier, por los alemanes, que consideraban este recinto portuario popular difícil de controlar, y por tanto lo derrumbaron. Le Panier, escenario preferente de las novelas de Izzo, de calles estrechas, de comercios pobres, de gente con pocos recursos o ningunos, pero de vida comunitaria y de solidaridad de vecinos, recuerda El Raval, este barrio del que Manuel Vázquez Montalbán decía que le sobraba a la burguesía.

La biografía de Jean-Claude Izzo en los años sesenta y setenta incluye una actividad que oscila entre la resistencia y la militancia : algo podemos leer al hilo de entrevistas y confesiones sobre su actuación en las filas de Pax Christi, un movimiento internacional cristiano a favor de la paz; algo sobre los quince kilos perdidos con motivo de una huelga de hambre durante el servicio militar para defender un concepto pacifista del ejército; algo sobre su temprana afiliación al PSU (Partido Socialista Unificado), encarnación de una izquierda socialdemócrata y autogestionaria opuesta a la guerra de Argelia. Quizá nos llame más la atención saber que en agosto del 69, cuando el PCF (Partido Comunista Francés) desaprueba la invasión de Checoslovaquia por las tropas del pacto de Varsovia, Jean-Claude Izzo adhiere al partido, llegando a ser secretario de sección. No hace falta evocar aquí la evolución política de Manuel Vázquez

11. La tres vieron la luz en Gallimard, respectivamente en 1995 (Série noire, 2370), 1996 (SN, 2422) y 1998 (SN, 2500) ; hay traducción española, por Matilde Sáenz López, publicada en Akal, respectivamente en 2003, 2004 y 2005.

12. Esta novela, una de las más logradas del autor, publicada en 1997 , se acaba de editar en España : Barcelona, Montesinos, 2010 (traducción de Josep Sarret Grau).

13. En C'est la rentrée! Nouvelles et souvenirs. Paris, Librio, 1997, p. 37-40.

14. Se evocan en "Nada quedó de abril..." ", primer poema de Una educación sentimental (Barcelona, Ediciones Saturno, 1967), los " grises atardeceres de máquina Sigma, / Wertheim, Singer / Singer, me inclino por la Singer / cansa menos los riñones [...]». 
Montalbán, conocida de todos, pero sí subrayar la obviedad de un paralelismo de itinerario bastante llamativo. Que se me permita una boutade: Izzo hubiera podido ser el autor de Praga, espléndido poemario de 1982 que Manuel Vázquez Montalbán dedica a la capital checoslovaca invadida y martirizada.

El nacimiento a la escritura de Jean-Claude Izzo también recuerda bastante el de Manuel Vázquez Montalbán, si bien el escritor francés no hizo sus primeros pinitos en la cárcel. Ya desde los estudios secundarios, con un periódico de instituto, Le Canard technique, y luego como colaborador, primero eventual y luego fijo, de la publicación regional comunista La Marseillaise, tantas veces citada en la trilogía, se dedica al periodismo. Paralelamente, ejerce varios oficios alimenticios, de los cuales algunos, el de vendedor de librería, el de bibliotecario, le permiten saciar su fuerte apetito cultural. Y cómo no, también escribe poesía. Son los años setenta y ochenta, años gratos que le permiten conciliar tres pasiones: cultivarse, escribir, militar. Huelga decir que, al igual que para Manuel Vázquez Montalbán, las tres pasiones están íntimamente ligadas.

Algunos títulos de poemarios que son otras tantas declaraciones de intención: Poèmes à haute voix (Poemas en alta voz), 1970; État de veille (Estado de vigilia), 1974; Braises, brasiers, brûlures (Brasas, braseros, quemaduras), 1974; Paysage de femmes (Paisajes de mujeres), 1975; Le réel au plus vif (La realidad en carne viva), 1976. Traduzco yo, sólo para dar idea de un universo literario que se está construyendo sobre los cimientos de una sensibilidad que se puede calificar de exacerbada. Al contrario de la poesía de Manuel Vázquez Montalbán, muy narrativa en su principio y que va evolucionando hacia un enfoque más esencialista hasta el fin del ciclo Memoria y deseo (1963-1990), la poesía de Jean-Claude Izzo ofrece de entrada una expresión depurada, áspera a veces como las rocas de la sierra de Marseilleveyre, que cierra la ciudad por el este. De pocas palabras, la poesía de Izzo busca la interioridad del ser, su verdad esencial, y la encuentra a veces en la armonía del paisaje mediterráneo; ésta es una pequeńa muestra:

Peut-être suis-je las. De n'attendre rien. À peine immobile, tel un cyprès. Sur l'oubli, je veille. Et la mort sinterroge. Je me refais une mémoire avec ces riens que sont chardons et pierres. La lumière aussi profonde que l'eau me rend l'avenir impossible. Je sais tout de ce qui brûle ou désaltère. Mais seuls, sans doute, les contraires cimentent l'aujourd'hui, ces insaisissables heures vers lesquelles mes doigts se tendent ${ }^{15}$.

Al igual que en el caso de Vázquez Montalbán, cuya obra poética ofrece claves semánticas y fórmulas expresivas que iluminan la obra narrativa, no se entendería la prosa de Izzo - las novelas, ya citadas y la última y más desesperada, Le soleil des mourants (El sol de los moribundos), su libro de cuentos, de título tan estremecedor: Vivre fatigue (Vivir cansa) ${ }^{16}$, - si no se tomara en cuenta la poesía. La escritura formularia, fragmentada, cincelada y desprovista de

15. Estrofa del poema «Fidélité», en Loin de tous rivages (Lejos de toda orilla). Nice, Éditions du Ricochet, 1996, p. 35.

16. Respectivamente Flammarion, 1999 y Librio, 1998. 
ornamentos superfluos de la narrativa debe su agilidad expresiva a la poesía. Como lo dice una estudiosa:

La phrase ne se déploie pas, elle se concentre, se replie sur elle-même. À l'image de son héros et de son créateur. Sa concision lui confere la force de l'airain en même temps que ses mots, délicats ou âpres, la dotent d'une fragilité cristalline $e^{17}$.

La poesía es para el autor Izzo lo que es el paisaje mediterráneo, y en especial el mar, para su criatura Fabio Montale: una fuente de vida, un espacio, biótico o textual, donde regenerarse, acaso ese lugar del que no se quisiera regresar tan caro a Manuel Vázquez Montalbán; un espacio amniótico, en una palabra:

Je m'étais dit que la solution à toutes les contradictions de l'existence était là, dans cette mer. Ma Méditerranée. Et je meétais vu me fondre en elle. Me dissoudre, et résoudre, enfin, tout ce que je n'avais jamais résolu dans ma vie, et tout ce que je ne résoudrai jamais (Soleá, 40).

Por lo demás, poesía, narrativa y periodismo son un canto a Marsella y a su gente. Una ciudad que, como Barcelona, tiene alma:

Marseille n'est pas une ville pour touristes. Il n'y a rien à voir. Sa beauté ne se photographie pas. Elle se partage. Ici il faut prendre partie. Se passionner. Etre pour ou contre. Etre, jusqu'au cou. Alors seulement, ce qui est à voir se donne à voir. Et là, trop tard, on se trouve en plein drame. Un drame antique où le héros, c'est la mort. À Marseille, même pour perdre, il faut savoir se battre (Total Khéops, 38).

También, como Barcelona, Marsella tiene una historia de luchas y resistencias. Marsella es un puerto, con lo que ello significa de horizontes lejanos, sueños, viajes, comercios y tráficos. La historia de la ciudad implica el mar, pero también lo que la industria y el comercio pueden sacar de la situación portuaria. La ciudad cosmopolita es cruce de varias poblaciones migrantes y desfavorecidas: entre 1945 y 1975, precisa Nadia Dhoukar, el crecimiento económico de Marsella atrae a más de 300000 inmigrados, los más desde África del norte y otros márgenes del Mediterráneo ${ }^{18}$. La mezcla de poblaciones, la recomposición social y cultural son tan importantes como lo son las aspiraciones frustradas.

Desde este punto de vista, Barcelona y Marsella conocen realidades comparables. Los barrios populares que crecen al norte de Marsella - en los que está destinado el inspector Fabio Montale en el primer episodio de la trilogía - son el equivalente de los barrios que Vázquez Montalbán evoca en Los mares del sur bajo el nombre de San Magín. 80000 viviendas sociales para una población de 250000 habitantes, entre los que la tasa de paro es el doble del promedio nacional. Entre 1975 y 1990, Marsella pierde más de 70000 puestos de trabajo en la construcción y la industria. Las primeras víctimas pertenecen como siempre a los sectores ya desfavorecidos de la sociedad.

17. Nadia Dhoukar, "Jean-Claude Izzo. Trajectoire d'un homme ", p. 19, en Jean-Claude Izzo, La trilogie Fabio Montale. Gallimard, 2005 (Folio policier, 420), p. 7-41.

18. "Jean-Claude Izzo. Trajectoire d'un homme", art. cit., p. 15. 
En Total Khéops, Montale evoca el sueño convertido en pesadilla del proyecto de polígono industrial, refinerías, metalurgia, química, de Fos-sur-mer, pueblo satélite de Marsella. Centra su relato en el itinerario de Mouloud, un obrero argelino:

Mouloud était à lui tout seul le rêve de l'immigration. Il fut l'un des premiers à être embauchés sur le chantier de Fos-sur-mer, fin 1970. [...] Une fois le premier lingot d'acier coulé, Fos n'était déjà plus qu'un mirage. Des milliers d'hommes restèrent sur le carreau. Mouloud avec eux. Mais il ne se découragea pas. Avec la CGT, il fit grève, il occupa le chantier, et se battit contre les CRS envoyés pour les déloger. Ils perdirent, bien sûr. On ne gagne jamais contre l'arbitraire économique des costards-cravate. [...] Et Mouloud, fiché comme agitateur, ne trouva plus de vrai travail. Seulement des petits boulots provisoires. Maintenant, il était manutentionnaire chez Carrefour (Total Khéops, 58-59).

Para este tipo de denuncia, Fabio Montale es el portavoz de Jean-Claude Izzo, más que Carvalho lo es de Vázquez Montalbán. Hay que tener en cuenta que el narrador de la Serie Carvalho se expresa de manera impersonal, manteniendo así al protagonista a la distancia necesaria para que medie la ironía, la mirada crítica, la eventual discrepancia ${ }^{19}$. Como varias veces lo afirmó el escritor barcelonés, Pepe Carvalho es un recurso técnico, que permite resolver la difícil cuestión del punto de vista sobre la realidad en el marco de una novela crónica. En la trilogía del escritor marsellés, el punto de vista de Montale lo invade todo, y se funde con la enunciación: la narración en primera persona hace de Montale un trasunto de Jean-Claude Izzo, quien expresa, por intermedio del protagonista, sus convicciones, sus aversiones humanas, sus recelos políticos, sus dudas sociales, sus credos éticos, en definitiva, su compromiso con la realidad. La escritura de Izzo, que sea la del periodista, del poeta o del narrador, es la de un hombre que sigue buscando y defendiendo valores humanos ya en desuso. Nada más claro en cuanto a los presupuestos éticos de su obra que la declaración de principios que abre Soleá:

On peut le dire une fois encore. Ceci est un roman. Rien de ce qui est raconté n'a réellement existé. Mais comme il m'est impossible de rester indifférent à la lecture quotidienne des journaux, mon histoire prend forcément les chemins du réel. Car en fin de compte c'est là que tout se passe, dans la réalité. Et l'horreur, dans la réalité, dépasse - et de loin - toutes les fictions possibles. Quant à Marseille, ma ville, toujours à mi-chemin entre la tragédie et la lumière, elle se fait, comme il se doit, l'écho de ce qui nous menace (Soleá, «Note de l'auteur», p. 7).

Este eco de la amenaza, esta capacidad que tiene el marco urbano para encarnar la tragedia endémica se debe en gran parte al tratamiento del espacio, del que diré ahora algunas palabras.

19. Las varias discrepancias que oponen el personaje al narrador se inventarían y escenifican en el monólogo teatral Antes de que el milenio nos separe, de 1997. La forma dramática del texto permite que el narrador sea sustituido por el propio escritor, y que el ajuste de cuentas cobre una dimensión unamuniana o pirandelliana. El texto fue editado por la Editorial Planeta en un estuche conmemorativo que reunía textos celebrando «El aniversario de un gran detective. Carvalho 25 años». 


\section{Tratamiento DEL ESPACio}

El marco urbano que ofrecen Marsella en la trilogía Montale y Barcelona en la serie Carvalho es un referente central convocado no como decorado de cartón piedra, sino como ente orgánico dotado de vida y capaz de evolucionar, crecer y morir. Saber leer la ciudad y descifrar sus códigos, conocer su realidad social, cultural y humana, interpretar sin equivocarse los múltiples signos que ofrece es condición sine qua non de la tarea del investigador de ficción. El paisaje urbano tiene suficiente entidad o corporeidad o seducción, tanto para Montale como para Carvalho, para que los dos personajes se enamoren de él.

A Manuel Vázquez Montalbán le gusta metaforizar la ciudad como si fuera una mujer, hablar de «las viejas carnes de la ciudad de su infancia», de la «cirugía estética» que sufre cuando la remodelan; el Barrio Chino es a veces evocado como «el corazón maligno de la ciudad portuaria» (Pianista, 16), y hasta calificado de «ingles de la ciudad». La metaforización del espacio es constante en la obra del escritor barcelonés, en tensión permanente y contradictoria entre memoria y deseo. La ciudad protege a Carvalho, dice el narrador de Asesinato en el Comité Central, "como las patrias o los recuerdos». La memoria permite mantener viva la patria espacial de la infancia, esa imagen de ciudad-patria que era Barcelona en tiempos de posguerra: Carvalho mantiene una «relación sensorial con la infancia» (Milenio II, 339), y le asedian imágenes rotas del paraíso perdido de su «infancia en la posguerra del barrio chino de Barcelona» (Milenio I, 15). De ahí que las mutaciones del panorama urbano, hasta de cualquier modificación del entorno, le provoquen un verdadero malestar: «[...] caminó por la avenida abierta por los bulldozers hacia las entrañas del país de su infancia del que ya no empezaba a quedar piedra sobre piedra.» (Hombre de mi vida, 235). Carvalho no entiende la evolución urbanística de su ciudad, producto en su opinión de "el espíritu de los nuevos tiempos, el espíritu de lo que algunos pedantes llamaban 'la posmodernidad' y que Carvalho pensaba era un tiempo tonto entre dos tiempos trágicos» (Hombre de mi vida, 19).

De Los mares del sur, Manuel Vázquez Montalbán dice que es «una novela urbana que utiliza a Barcelona como escenario y como metáfora de la Historia y el Universo» (Barcelonas, 334). La metáfora de la ciudad como cuerpo femenino también está presente bajo la pluma de Izzo: «Marseille, avait-il alors pensé, est une femme qui s'offre à ceux qui arrivent par la mer» (Marins perdus, 13).

Marsella viene a ser en las novelas de Izzo un verdadero personaje, y el relato se enuncia siempre en primera persona para mejor subrayar la dimensión autobiográfica de la unión del protagonista con la ciudad.

Esta dimensión metafórica, sin embargo, no impide que los personajes se acerquen al panorama urbano con total lucidez. Jean-Claude Izzo en especial procura permanentemente inscribir este paisaje en la verdad de su representación y presentar la ciudad tal como es, no como un objeto pensado para el turista o para el lector: "Je traversais Marseille, mais je ne voyais déjà plus rien de la ville. 
Désormais, je ne connaissais que sa violence sourde et son racisme à fleur de peau. J'oubliais que la vie ne se résumait pas à cela» (Total Khéops, 87).

Montale no ignora nada de la realidad sociológica de la ciudad, del reparto de las poblaciones en función de los niveles sociales:

Depuis sa création, javais à peine fait une dizaine de fois le trajet de la ligne 1 du métro. Castellane-La Rose. Des quartiers aisés, où sétait déplacé le centre-ville avec ses bars, restaurants, cinés, aux quartiers nord, où il n'y avait aucune raison d'aller sans y être obligé (Total Khéops, 74).

Y sobre todo, capta perfectamente la especificidad negativa de las zonas más populares, de esos barrios que Manuel Vázquez Montalbán califica de «ingles de la ciudad»:

J'ai garé ma $R 5$ sur le parking de La Paternelle. Une urbanisation maghrébine. Ce n'était pas la plus dure. Ni la moins pire. Il était à peine dix heures et il faisait déjà très chaud. Là-bas le soleil pouvait taper dur sur tout ce qu'il voulait. Pas un arbre, rien. Les blocs. Le parking. Le solaire. Et au loin, la mer. L'Estaque et son port. Tel un autre continent. Je me souviens que Charles Aznavour chantait: La misère est moins dure au soleil. Il n'était sans doute pas venu jusque là. Jusqu'à ces tas de merde et de béton (Total Khéops, 52).

La ciudad de Montale también se estratifica de manera similar a la de Carvalho: la ciudad del pasado está siempre presente, medio oculta bajo capas de memoria y olvido: «Volví a bajar la calle del Panier. Mis recuerdos resonaban más que el paso de los transeúntes.», dice Montale (Total Khéops, 13). Medio oculta también debajo de las obras de renovación y remodelación que impone el mecanismo del crecimiento capitalista, el concepto del progreso material, con el descaro consiguiente de la segregación:

Les arabes sétaient regroupés dans le centre, on leur avait donc laissé le centre. Avec dégoût pour la promenade Belzunce ou la rue d'Aix et toutes les rues, étroites, lépreuses, qui allaient de Belzunce aux allées de Meilhan ou à la gare Saint-Charles. Les rues des putes. Avec des immeubles insalubres et des hôtels pouilleux. Toutes les migrations avaient transité dans ces rues. Jusqu'à ce qu'une rénovation ne les expulse vers la périphérie. Une nouvelle rénovation avait commencé, et la périphérie était aux limites de la ville. À Septèmesles-Vallons. Vers les Pennes-Mirabeau. Loin, à chaque fois plus loin. Hors de Marseille (TotalKhéops, 170-171).

Manuel Vázquez Montalbán evoca algo similar, es decir otro avatar de la exclusión social, cuando habla de «[... ] nuevos edificios que trataban de expulsar de aquella Barcelona vieja la arqueología humana de sus pobladores lumpen» (Hermano pequeño, 70). Ambos escritores comparten la misma desilusión crítica, y la misma necesidad de entender la dualidad fundamental de su ciudad : dualidad espacial, que reparte y opone las clases sociales; dualidad temporal, que contrasta la ciudad mitificada del pasado con la ciudad atormentada del presente y hace que, para un personaje montalbaniano, «la vista era asaltada por la ambigüedad de un paisaje en el que no se sabía donde empezaban las destrucciones y donde empezaban las construcciones» (Laberinto griego, 76).

Tanto la poética de Jean-Claude Izzo como la de Manuel Vázquez Montalbán implican una lectura temporal del espacio y una lectura espacial del tiempo; esa 
simultaneidad de lecturas es necesaria para acceder a los diferentes niveles, o círculos concéntricos, que dibuja la escritura de la ciudad:

1. la Marsella o la Barcelona del recuerdo, con la dimensión mitificada de la infancia y del paraíso perdido;

2. la ciudad escenario de la investigación, que sirve de telón de fondo al despliegue del eterno drama del hombre lobo para el hombre, que se actualiza en términos de explotación y opresión socio-económicas;

3. la ciudad metáfora, con la que también se despliega un juego eterno, el de la relación de amor-odio, probable explicación, entre paréntesis, al hecho de que tanto a Montale, con su casita en Les Goudes, como a Carvalho, con su torre en Vallvidrera, les haga falta tener un lugar fronterizo, madriguera, espacio amniótico donde refugiarse y protegerse de su relación pasional con la urbe y «desde donde contemplar la ciudad como a una desconocida» (Soledad del manager), primer paso para el despliegue de una tentación, una utopía, que también caracteriza ambos universos literarios: el de la huida, en especial de la huida hacia el sur.

"Leer hasta entrada la noche y en invierno viajar hacia el sur», es un leitmotiv del narrador montalbaniano heredado de la poesía de T. S. Eliot, "I read, much of the night, and go south in Wintern ${ }^{20}$; esta dimensión mítica del sur, al encarnarse en un espacio referencialmente identificable, permite, de manera quizá más nítida en el autor barcelonés que en el escritor marsellés, convertir el marco espacial en un elemento funcional del relato, en un verdadero motor narrativo.

Los mares del Sur cuenta la investigación llevada a cabo por Pepe Carvalho sobre un rico promotor inmobiliario, Carlos Stuart Pedrell, encontrado muerto a puñaladas en un solar de la periferia de Barcelona, cuando todo el mundo pensaba que se había marchado a revivir el sueńo del pintor Gauguin en alguna isla de los mares del sur. Después de múltiples peripecias, se impone al detective una metáfora, «El sur es la otra cara de la luna» (Mares del sur, 106, 205), que funciona como una clave: hay que sustituir el sur de los suburbios proletarios al norte de los barrios burgueses para entender lo sucedido. Pepe Carvalho constata en efecto que, en la zona opuesta al solar donde apareció el cadáver, es decir al sur de la ciudad, está San Magín. San Magín, nombre imaginario para un espacio real, mixto de Hospitalet y Bellvitge, es una de aquellas ciudades satélites fruto del desarrollo artificial que impulsó el franquismo y de la expansión urbana anárquica que promocionó José María de Porcioles, alcalde de Barcelona de 1957 a $1973^{21}$. San Magín, en realidad ciudad-dormitorio para mano de obra inmigrada, herejía urbanística cometida por Stuart Pedrell y sus socios.

20. El verso pertenece al poema "The burial of the dead» qui ouvre le recueil The waste land (1921-1922); véase T. S. Eliot, Poésie (édition bilingue, traduction de Pierre Leyris). Paris, Éditions du Seuil, 1947.

21. San Magín es calificada en el discurso oficial de «ciudad nueva par una vida nueva [...] inaugurada por Su Excelencia el jefe de Estado el 24 de junio de 1966» (Mares del sur, 110). 
Ahí se instala a su vez Pepe Carvalho, viajero perdido por los mares del sur urbanísticos, de los que puede tener así una percepción exacta con valor de denuncia. Los términos de la denuncia son conocidos y no voy a insistir en ellos. Lo que sí quiero subrayar es que, en este universo dejado de la mano de Dios, Carlos Stuart Pedrell era percibido como un ser desfasado, desplazado, «Era un intruso» (Mares del sur, 203), según el viejo Briongos. De ahí que Pepe Carvalho reconstituya la desaparición de Stuart Pedrell en términos que son una referencia constante al mito de la evasión o de la huida:

Tú te fuiste a San Magin a ver tu obra de cerca, a ver cómo vivian tus canacos en las cabañas que les habias preparado. [...] Seguramente fuiste en metro para una mayor identidad entre forma y fondo del largo viaje a los mares del Sur. (Mares del sur, 107)

Cruzar la frontera entre el norte y el sur (Mares del sur, 205) permite en resumidas cuentas contrastar dos mundos: el mundo de los verdugos, al que pertenecía el promotor y el de las víctimas, al que, por remordimiento o toma de conciencia, Stuart Pedrell intentó agregarse.

Un intento, obviamente, condenado de antemano al fracaso. La investigación muestra que es vano buscar la otra cara de la luna, utópico buscar la salvación, o la redención de los pecados, en la huida. El determinismo de clase por una parte y los mecanismos de la opresión por otra parte no se pueden cambiar, cualesquiera que sean las tomas de conciencia individuales. Los mares del sur dicen, mediante una espléndida transposición que es una espacialización del mito edénico, que el mundo no ofrece más solución que la melancolía.

¿Lección pesimista? Cuando se cierra sobre Stuart Pedrell la trampa del espacio cerrado insular se abre el espacio del relato. El proyecto inicial del promotor sólo se puede realizar en versión narrativa. Literalmente: si las islas de los mares del sur de Stuart Pedrell son tan irrisorias, es porque en definitiva, la única isla que permanece al alcance de las aspiraciones humanas es la del texto. El Sur ya ni siquiera es una metáfora, sólo una posibilidad de viaje en los mares de la literatura.

Y por este motivo, en otro archipiélago que es el de las novelas de Jean-Claude Izzo, uno de los protagonistas más humanos y de más ética de toda la literatura policiaca del siglo XX muere al final de su tercera aventura, implacablemente matado por la Mafia. Una Mafia de ficción que, evidentemente, y a pesar de la exactitud de la representación factual, no es más que la encarnación literaria de la tragedia del hombre contemporáneo.

\section{Bibliografía}

\section{Textos}

Izzo Jean-Claude, Total Kheops. Gallimard, 1995 (Série noire, 2370).

- Chourmo. Gallimard, 1996 (Série noire, 2422).

— Soleá. Gallimard, 1998 (Série noire, 2500). 
— Loin de tous rivages. Nice, Éditions du Ricochet, 1996.

— Les marins perdus. Flammarion, 1997 (Gulliver).

— «Une rentrée en bleu de chine», dans C'est la rentrée! Nouvelles et souvenirs. Paris, Librio, 1997, p. 37-40

- Vivre fatigue. Librio, 1998.

— Le soleil des mourants. Flammarion, 1999.

— Marseille. Photographies de Daniel Mordzinski. Paris, Hoëbeke, 2000.

Vázquez Montalbán Manuel, Una educación sentimental. Barcelona, Ediciones Saturno, 1967.

- Los mares del Sur. Barcelona, Planeta, 1979.

- Barcelonas. Barcelona, Empúries, 1987.

- Antes de que el milenio nos separe. Barcelona, Planeta, 1997 (Estuche conmemorativo Carvalho 25 ańos).

- El pianista. Barcelona, Seix Barral, 1985.

- Memoria y deseo. Obra poética (1963-1990). Barcelona, Grijalbo Mondadori, 1996.

- Le désir de mémoire. Entretien avec Georges Tyras. Vénissieux, Éditions Paroles d'Aube, 1997.

- El hombre de mi vida. Barcelona, Planeta, 2000.

- Milenio Carvalho I y II. Barcelona, Planeta, 2003.

\section{Obras de consulta}

Demougin Françoise, «Izzo. Un étonnant voyageur», Recherches et travaux, n 59, 2001, Contraintes et dérives d'écriture, p. 141-149.

Dhoukar Nadia, «Jean-Claude Izzo. Trajectoire d'un homme», en Jean-Claude Izzo, $L a$ trilogie Fabio Montale. Gallimard, 2005 (Folio policier, 420), p. 7-41.

Dupont Pascal, «Izzo ou l'utopie en rade», L'Express, 20 mars 1997.

Eliot Thomas Stearn, Poésie (édition bilingue, traduction de Pierre Leyris). Paris, Éditions du Seuil, 1947.

Nassif Philippe, «La melting culture de Marseille la rebelle», L'Événement du Jeudi, 3 avril 1997.

Resina Joan Ramón, Un cadáver en la cocina. La novela criminal en la cultura del desencanto. Barcelona, Anthropos, 1997 (Contemporáneos, 48). 